\title{
Creep Resistance of Polyethylene-based Nanocomposites
}

\author{
Abdulaziz S. Alghamdi \\ Mechanical Engineering Department, \\ College of Engineering, University of Hail, \\ Hail, Saudi Arabia \\ asbg945@hotmail.com
}

\begin{abstract}
The purpose of this work is to investigate the effects of carbon black (CB), carbon nanotubes (CNTs) and nanoclay sheets addition on the creep behavior of polyethylene-based nanocomposites synthesized with an in-house processing method. A blend of $75 \mathrm{wt} \% \%$ UHMWPE and $25 \mathrm{wt} \%$ HDPE, abbreviated to $\mathrm{U} 75 \mathrm{H} 25$, was used as the hybrid PE matrix to accommodate the nanofillers. A $0.5 \mathrm{wt}$ \% of CB, CNTs or nanosheets clay was embedded separately into the blend matrix in order to improve the creep resistance. The scanning electron microscope (SEM) and transmission electron microscope showed that the nanofillers were homogeneously dispersed in the $\mathrm{U} 75 \mathrm{H} 25$. The addition of just $0.5 \mathrm{wt} . \%$ nanoclay resulted in a significant increase in the creep resistance of the polyethylene blend. Conversely, the addition of $\mathrm{CB}$ or CNTs caused a reduction in the creep resistance. The embedding of CNTs into the matrix resulted in creep behavior almost close to the creep behavior of pure UHMWPE. The Burger's model was employed to understand the effect of the nanoparticle addition on the creep mechanism.
\end{abstract}

Keywords-UHMWPE; HDPE; polymer; creep; nanocomposite; polyethylene

\section{INTRODUCTION}

Polyethylene (PE) is the most widely used thermoplastic because of its outstanding mechanical properties, such as moisture absorption, chemical resistance, high toughness and ease of processing [1]. It was found that the incorporation of various nanofillers can lead to a significant improvement in the polyethylene composite properties which can be used in many applications such as packaging, electrical and thermal energy storage, automotive, and biomedical [1-6]. Recently, new polyethylene nanocomposites have been developed with the use of various processing methods, different types, and amounts of reinforcements [7-16]. These nanocomposites can be a cost-effective alternative to the high cost advanced composites and can be widely used in various industrial applications [1]. However, achieving uniform dispersion of the nanoparticles is still an important scientific and technological challenge in nanocomposite fabrication. Poor dispersion of the nanofillers, weak interaction between the filler and the matrix, and agglomeration can lead to the reduction of the mechanical properties [9]. In [10], it was found that the embedding of MWCNT and nanoclay into the polyethylene matrix increased significantly hardness, elastic modulus and indentation resistance of polyethylene-based nanocomposites. In this work, different types of nanofillers with different geometric shapes were used in order to improve the creep resistance of the UHMWPE/HDPE. The volume of fractions was kept at low percentage to minimize the effect of agglomeration, especially for $\mathrm{CB}$ and $\mathrm{CNT}$. The creep response was analyzed using the Burger's model.

\section{EXPERIMENTAL WORK}

\section{A. Materials}

The materials tested in this study were UHMWPE/HDPE blended polymers with various nanofillers. Nascent UHMWPE powders (Sabic ${ }^{\circ}$ UHMWPE3548) were purchased from SABIC, having an average molecular weight of $3 \times 106 \mathrm{~mol} / \mathrm{g}$. HDPE powders (ExxonMobil TM HDPE HMA014) were purchased from ICO Ltd. Carbon black (CB) powder with the commercial product name, black pearls ${ }^{\circledR} 4040$ (BP4040) and average particle diameter of $28 \mathrm{~nm}$ was provided by Cabot Corporation. Natural hectorite nanoclay was supplied by Elementis specialties. Multi-wall Nanotubes (MWNT) with diameters in the range of $5 \mathrm{~nm}$ to $50 \mathrm{~nm}$, were provided by Nanocyl. Butylated hydroxytoluene and Tris (nonylphenyl) phosphate, supplied by Sigma-Aldrich, were used as primary and secondary antioxidants, to maintain the long term thermal stability and melt processing stability, respectively.

\section{B. Processing}

An in-house pre-mix technology was used to incorporate the nanofillers into the UHMWPE and HDPE powders. A twinscrew extruder was then used to blend the UHMWPE and HDPE powders pre-mixed with $0.5 \mathrm{wt} \%$ of $\mathrm{CB}$, carbon nanotubes (CNT) or nanoclay to form nano-filled UHMWPE/HDPE composites. A blend of $75 \mathrm{wt} . \%$ UHMWPE and $25 \mathrm{wt} . \% \mathrm{HDPE}$, abbreviated to $\mathrm{U} 75 \mathrm{H} 25$, was used as the hybrid PE matrix to accommodate the nanofillers. During processing, the mixing temperature was controlled using five zones from feeding port to die, the processing parameters are shown in Table I. Compression moulding was used to mould the nanocomposite materials. The raw material was placed into a mould $(100 \mathrm{~mm} \times 100 \mathrm{~mm} \times 1.65 \mathrm{~mm})$, and then heated to $190^{\circ} \mathrm{C}$, which is higher than the melting point of the composite (approximately $135^{\circ} \mathrm{C}$ ). Various mould pressures (154, 232, 
309 , and $386 \mathrm{MPa}$ ) were studied in order to optimize material properties such as hardness and crystallinity. Various holding times at maximum pressure $(10,15$ and $30 \mathrm{~min})$ were also used to identify the most appropriate moulding parameters. The optimal moulding pressure and holding time were $309 \mathrm{MPa}$ and $15 \mathrm{~min}$ respectively, which resulted in the highest values of hardness and crystallinity. After compression moulding, the mould was cooled to room temperature with the use of water. Then, the specimens were cut from the plaques into a dumbbell shape using a die punch cutter with the following dimensions: $75 \mathrm{~mm}$ overall length, $25 \mathrm{~mm}$ length of narrow parallel-sided portion, $12.5 \mathrm{~mm}$ width at the ends, $4 \mathrm{~mm}$ width of narrow portion and $1.65 \mathrm{~mm}$ thickness.

TABLE I. PROCESSING METHOD PARAMETERS

\begin{tabular}{|c|c|c|c|c|c|c|}
\hline Extruder & \multicolumn{5}{|c|}{ Processing Temperature $\left({ }^{\mathbf{O}} \mathbf{C}\right)$} \\
\cline { 2 - 7 } Speed (rpm) & Zone 1 & Zone 2 & Zone 3 & Zone 4 & Die & Cooling \\
\hline 190 & 220 & 250 & 260 & 270 & 280 & water \\
\hline
\end{tabular}

\section{Mechanical Testing and Characterization.}

In order to characterize the nanofiller dispersion and the microstructure of the $\mathrm{U} 75 \mathrm{H} 25$ nanocomposites, several experimental techniques were used. These included differential scanning calorimetry (DSC), scanning electron microscopy (SEM) and transmission electron microscopy (TEM). DSC, (TA instruments, Shimadzu DSC60) was used to analyze the effect of different compression moulding parameters and nanofiller types on the crystallinity of the blend and nanocomposites. The specimens, with average mass of $5 \pm 0.2 \mathrm{mg}$, were sealed in aluminium pans and heated from $20^{\circ} \mathrm{C}$ to $180^{\circ} \mathrm{C}$ at a rate of $10^{\circ} \mathrm{C}$ per minute. The mass fraction degree of crystallinity was then determined by comparing the heat of fusion with that for fully crystalline polyethylene at the equilibrium melting point $(290 \mathrm{~kJ} / \mathrm{kg})$ [17]. The surface morphology was investigated using a LEO 440 SEM from Leo Electron Microscopy Ltd and Philips XL30 ESEM-FEG from FEI Company. The dispersion of the nanofillers was studied after fracturing the samples in liquid nitrogen, and then coating them using platinum. A JEOL 2000FX TEM from JEOL Ltd. was used to analyze the dispersion of nanofillers into the blend matrix. Tensile creep tests were carried out using an Instron 3366 tensile testing machine from Instron Corporation) at room temperature $\left(22 \pm 2^{\circ} \mathrm{C}\right)$.

\section{Burger's Model.}

Creep modeling and analysis is important to determine time response, which leads to understanding chain dynamics. The Burger's model, which is a combination of Kelvin-Voigt and Maxwell elements, is the most used model to describe the linear viscoelastic behavior of composites. The total strain as a function of time can be obtained from (1) [18]:

$$
\varepsilon_{B}=\frac{\sigma}{E_{M}}+\frac{\sigma}{E_{K}}\left(1-e^{-t / \tau}\right)+\frac{\sigma}{\eta_{M}} t
$$

where $E_{M}$ and $\eta_{M}$ are the elastic and viscous components of Maxwell model, $\tau=\eta_{\mathrm{K}} / \mathrm{E}_{\mathrm{K}}$ is the retardation time taken to produce $63.2 \%$ of the total deformation in the Kelvin unit, $\eta_{\mathrm{K}}$ and $\mathrm{E}_{\mathrm{K}}$ are elastic and viscous components of Kelvin model.

\section{RESULTS AND DISCUSSION}

\section{A. Nanofillers Dispersion}

Figure 1 shows the SEM images for the microstructure of $\mathrm{U} 75 \mathrm{H} 25$ /nanofillers. It can be seen that $\mathrm{CB}$, nanoclay and CNTs are dispersed homogenously in the U75H25 matrix. However, small agglomeration of the $\mathrm{CB}$ nanofillers can be observed, which can lead to a reduction of load carrying capacity between $\mathrm{CB}$ and the polymer matrix. Similarly, these CB nanofillers agglomerations have been observed in the TEM image, as seen in Figure 2(a). Moreover, Figure 1(c) shows good dispersion of CNTs into the polyethylene matrix. Single clay nanosheet and CNT can be seen in Figures 2(b) and 2(c), respectively. This indicates a uniform distribution of both clay nanosheets and CNTs into the blend matrix.

(a)

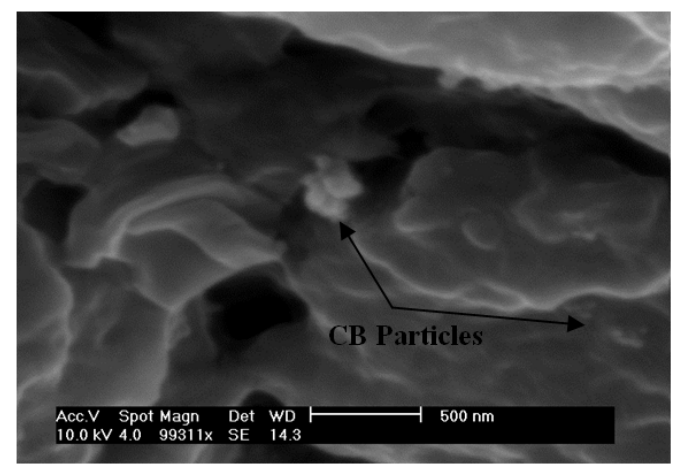

(b)

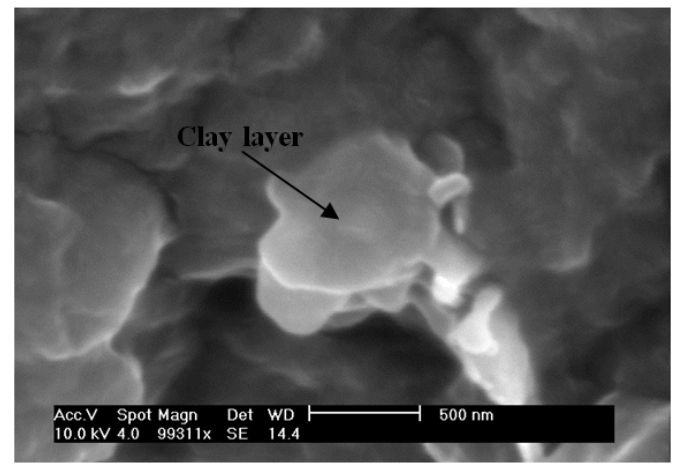

(c)

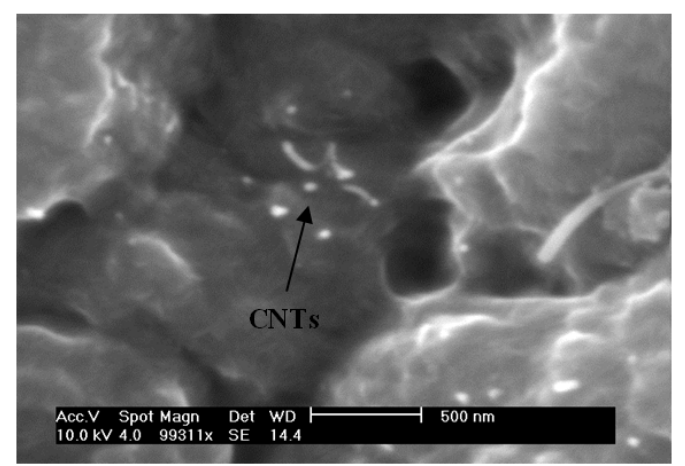

Fig. 1. SEM images for the microstructure of (a) U75H25-0.5wt.\%, (b) U75H $25-0.5$ wt. \% clay, and (c) U75H $25-0.5 \mathrm{wt} . \% \mathrm{CNTs}$ 
(a)

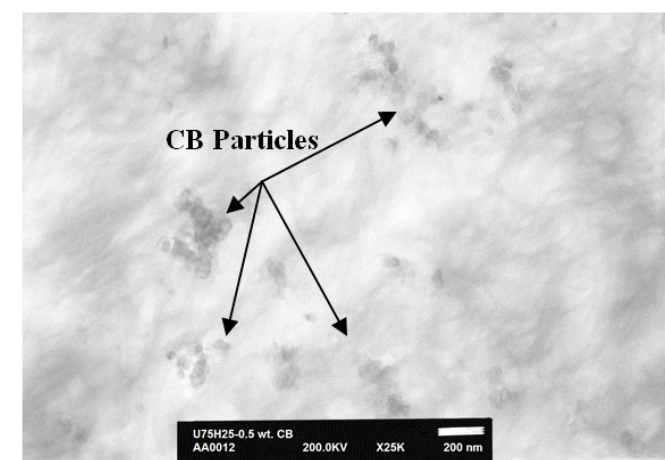

(b)

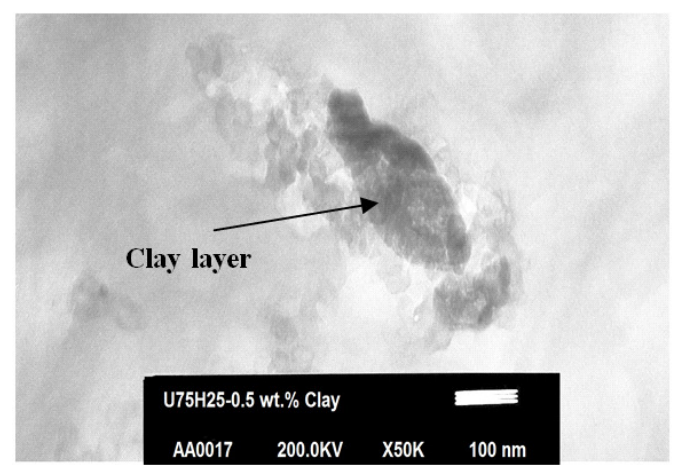

(c)

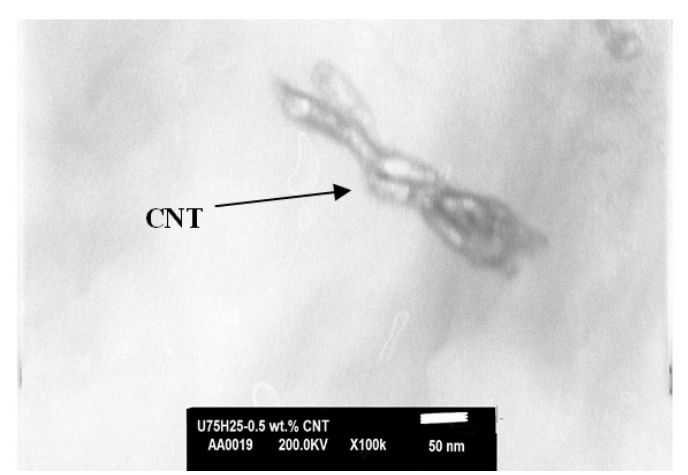

Fig. 2. TEM images for the microstructure of (a) U75H25-0.5wt.\%, (b) U75H25-0.5wt.\% Clay, and (c) U75H25-0.5wt.\% CNTs

\section{B. Thermal Analysis}

Table II presents the DSC results for $\mathrm{U} 75 \mathrm{H} 25$ and its nanocomposites. It can be seen that the addition of $0.5 \mathrm{wt} . \% \mathrm{CB}$ nanoparticles has no effect on crystallinity, however crystallinity is increased significantly with the addition of $0.5 \mathrm{wt} . \%$ clay nanosheets. The incorporation of $0.5 \mathrm{wt} . \%$ CNTs resulted in a slight reduction in the crystallinity value. These changes in the crystallinity values can be attributed to the effect of nanofiller shapes and the interaction between the nanofillers and the polyethylene matrix.

TABLE II. THERMAL PROPERTIS OF HDPE-BASED NANOCOMPOSITES

\begin{tabular}{|c|c|}
\hline Materials & Crystallinity \% \\
\hline UHMWPE & 53.3 \\
\hline U75H25 & 55.3 \\
\hline U75H25-0.5wt.\% CB & 55.2 \\
\hline U75H24-0.5wt.\% Clay & 69 \\
\hline U75H25-0.5wt.\% CNT & 50 \\
\hline
\end{tabular}

\section{Tensile Creep Results}

Figure 3 shows the effect of the blending of HDPE on the creep resistance of UHMWPE and the effects of the addition of nanofillers on the creep resistance of $\mathrm{U} 75 \mathrm{H} 25$ blend. It can be seen that blending $25 \mathrm{wt} . \%$ of HDPE with $75 \mathrm{wt} . \%$ UHMWPE resulted in an increase in the creep resistance by $32 \%$. This can be proposed to the influence of HDPE chains and spherulite properties on the mobility during creep. The viscoelastic behavior in semi-crystalline polymers such as UHMWPE and HDPE is a combination of crystalline and amorphous phase's mobility and the changes in these microstructures can lead to significant variation in the polymer properties. The addition of $\mathrm{CB}$ and CNTs nanofillers resulted in a reduction in the creep resistance of the $\mathrm{U} 75 \mathrm{H} 25$ blend. This can be attributed to the agglomerations of the nanofillers, which lead to a reduction in the surface to volume ratio and apply as defects in the microstructure. Polyethylene is a nonpolar polymer; therefore, the interaction between the nanofillers and the polyethylene matrix is almost weak. This can affect the effectiveness of load transfer between the matrix and the nanofiller, which then affects mechanical properties. However, the addition of 2D plate-like nanofillers showed a significant improvement in the creep resistance of the polyethylene blend. The addition of only $0.5 \mathrm{wt} . \%$ of clay nanosheets resulted in $22 \%$ increase in the creep resistance. This can be attributed to the good dispersion, interaction between nanoclay and polyethylene matrix, the increase in crystallinity and the plate-like shape of nanoclay.

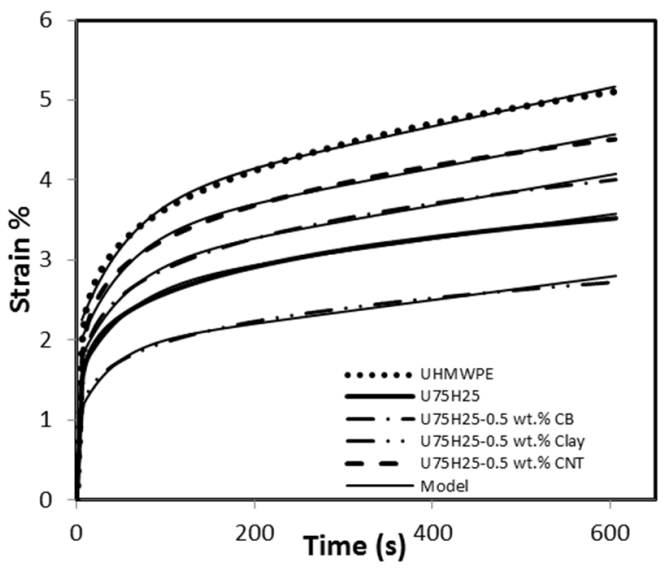

Fig. 3. Effect of GNSs addition on the micro-hardness values.

\section{Constitutive Modeling}

As shown in Figure 3, curves fitting are in a satisfactory agreement with the experimental data. The data were fitted to the Burger's model, all parameters being obtained by minimizing the sum of the squared differences between the actual and calculated strains, using the solver in Excel. Table II shows the Berger's model parameters that indicate an increasing in the values with blending $25 \mathrm{wt} . \%$ HDPE with 75wt.\% UHMWPE. Further increasing can be observed with the addition of plate-like clay nanosheets. The elasticity $\mathrm{E}_{\mathrm{M}}$ and the stiffness of the amorphous phase $\mathrm{E}_{\mathrm{K}}$ of the blend have increased by $32 \%$ by the addition of nanoclay. The parameter $\eta_{M}$ represents the irrecoverable creep strain, which also 
increased with the addition of nanoclay. This indicates that a reduction in the dashpot flow can occur, which leads to a reduction in the permanent deformation. However, retardation time, where $\tau$ is the delayed response to the applied stress for the $\mathrm{U} 75 \mathrm{H} 25-0.5 \mathrm{wt} . \%$ clay, is less than the retardation time for the blend and the UHMWPE. Conversely, the addition of CB and CNTs nanofillers to the blend matrix shows a reduction in elasticity, stiffness and in the irrecoverable creep strain.

TABLE III. BURGER'S MODEL PARAMETERS

\begin{tabular}{|c|c|c|c|c|c|}
\hline Material & $\begin{array}{c}\mathbf{E}_{\mathbf{M}} \\
(\mathbf{M P a})\end{array}$ & $\begin{array}{c}\boldsymbol{\eta}_{\mathbf{M}}(\mathbf{x 1 0} \\
\mathbf{M P a . s})\end{array}$ & $\begin{array}{c}\mathbf{E}_{\mathbf{K}} \\
(\mathbf{M P a})\end{array}$ & $\begin{array}{c}\boldsymbol{\tau} \\
(\mathbf{s})\end{array}$ & $\begin{array}{c}\boldsymbol{\eta}_{\mathbf{K}} \\
(\mathbf{M P a . s})\end{array}$ \\
\hline UHMWPE & 445 & 381 & 561 & 56.1 & 31472.1 \\
\hline U75H25 & 617 & 605 & 789 & 53.4 & 42132.6 \\
\hline U75H25-0.5wt.\% CB & 558.7 & 480 & 724 & 52.3 & 37865.2 \\
\hline $\begin{array}{c}\text { U75H24-0.5wt.\% } \\
\text { Clay }\end{array}$ & 907 & 629 & 1020 & 37.7 & 38454 \\
\hline $\begin{array}{c}\text { U75H25-0.5wt.\% } \\
\text { CNT }\end{array}$ & 497 & 445 & 626 & 53.6 & 33553.6 \\
\hline \multicolumn{4}{|r|}{}
\end{tabular}

\section{CONCLUSION}

The main findings in this work are summarized as follows:

- Blending 25wt.\% of HDPE with 75wt.\% UHMWPE resulted in a significant increase in the creep resistance.

- The addition of low weight fraction of plate-like nanoclay leads to further improvement in the creep resistance of the $\mathrm{U} 75 \mathrm{H} 25$ blend.

- The embedding of CB and CNTs into the blend matrix resulted in a reduction in the creep resistance, which can be attributed to the weak interaction between the filler and the polyethylene matrix. Moreover, the agglomeration of these types of nanofillers can reduce the surface to volume ratio, which can significantly affect the load transfer between the matrix and the filler.

- Elasticity, stiffness and the irrecoverable creep strain have increased with the addition of plate-like nanoclay.

\section{REFERENCES}

[1] P. N. Khanam, M. A. A. Maadeed, "Processing and characterization of polyethylene-based composites", Advanced Manufacturing: Polymer \& Composites Science, Vol. 1, No. 2, pp. 63-79, 2015

[2] A. Sari, "Form-stable paraffin/high density polyethylene composites as solid-liquid phase change material for thermal energy storage: preparation and thermal properties", Energy Conversion and Management, Vol. 45, No. 13-14, pp. 2033-2042, 2004

[3] K. M. Manu, S. Soni, V. R. K. Murthy, M. T. Sebastian, "Ba(Zn1/3Ta2/3)O3 ceramics reinforced high density polyethylene for microwave applications", Journal of Materials Science: Materials in Electronics, Vol. 24, No. 6, pp. 2098-2105, 2013

[4] T. K. Dey, M. Tripathi, "Thermal properties of silicon powder filled high-density polyethylene composites", Thermochimica Acta, Vol. 502, No. 1-2, pp. 35-42, 2010

[5] L. Fang, Y. Leng, P. Gao, "Processing of hydroxyapatite reinforced ultrahigh molecular weight polyethylene for biomedical applications", Biomaterials, Vol. 26, No. 17, pp. 3471-3478, 2005

[6] Q. Zhang, S. Rastogi, D. Chen, D. Lippits, P. J. Lemstra, "Low percolation threshold in single-walled carbon nanotube/high density polyethylene composites prepared by melt processing technique", Carbon, Vol. 44, No. 4, pp. 778-785, 2006
[7] A. S. Alghamdi, I. A. Ashcroft, M. Song, D. Cai, "Morphology and strain rate effects on heat generation during the plastic deformation of polyethylene/carbon black nanocomposites", Polymer Testing, Vol. 32, No. 6, pp. 1105-1113, 2013

[8] A. S. Alghamdi, I. A. Ashcroft, M. Song, D. Cai, "Nanoparticle type effects on heat generation during the plastic deformation of polyethylene nanocomposites", Polymer Testing, Vol. 32, No. 8, pp. 1502-1510, 2013

[9] A. S. Alghamdi, I. A. Ashcroft, M. O. Song, "Creep resistance of novel polyethylene/carbon black nanocomposites", International Journal of Materials Science and Engineering, Vol. 2, No. 1, pp. 1-5, 2014

[10] A. S. Alghamdi, I. A. Ashcroft, M. O. Song, "High temperature effects on the nanoindentation behaviour of polyethylene-based nanocomposites", International Journal of Computational Methods and Experimental Measurements, Vol. 3, No. 2, pp. 79-88, 2015

[11] C. V. Gorwade, A. S. Alghamdi, I. A. Ashcroft, V. V. Silberschmidt, M. O. Song, "Finite Element Analysis of the High Strain Rate Testing of Polymeric Materials", Journal of Physics: Conference Series, Vol. 382, ArticleID 012043, 2012

[12] A. S. Alghamdi, "Nanoparticle type effects on the scratch resistance of polyethylene-based nanocomposites", International Journal of Advanced and Applied Sciences, Vol. 4, No. 4, pp. 1-6, 2017

[13] D. R. Paul, L. M. Robeson, "Polymer nanotechnology: Nanocomposites", Polymer, Vol. 49, No. 15, pp. 3187-3204, 2008

[14] M. Rahmat, P. Hubert, "Carbon nanotube-polymer interactions in nanocomposites: A review", Composites Science and Technology, Vol. 72, No. 1, pp. 72-84, 2011

[15] X. Jiang, L. T. Drzal, "Multifunctional High-Density Polyethylene Nanocomposites Produced by Incorporation of Exfoliated Graphene Nanoplatelets 2: Crystallization, Thermal and Electrical Properties", Polymer Composites, Vol. 33, No.4, pp. 636-642, 2012

[16] A. S. Alghamdi, "Synthesis and mechanical characterisation of high density polyethylene/graphene nanocomposites", Engineering, Technology \& Applied Science Research, Vol. 8, No. 2, pp. 2814-2817, 2018

[17] S. Humbert, O. Lame, G. Vigier, "Polyethylene yielding behaviour: What is behind the correlation between yield stress and crystallinity?", Polymer, Vol. 50, No. 15, pp. 3755-3761, 2009

[18] W. N. Findley, J. S. Lai, K. Onaran, Creep and Relaxation of Nonlinear Viscoelastic Materials, Dover Publications, 1989 